ANNALES

UNIVERSITATIS MARIAE CURIE-SKŁODOWSKA

LUBLIN - POLONIA

VOL. LXX, 1

SECTIO AA

2015

\title{
Effect of Pluronics and surfactant adsorption onto dolomite suspension zeta potential and stability
}

\author{
Anna Kozak and Zygmunt Sadowski* \\ Wroclaw University of Technology, \\ Wybrzeże Wyspiańskiego 27, 50-370 Wroctaw \\ *e-mail: zygmunt.sadowski@pwr.wroc.pl
}

Two kinds of Pluronics (PEO-PPO-PEO triblock copolymers) were used in these studies. They have mixed with anionic surfactant (sodium oleate). The adsorption isotherms of surfactant and copolymer-surfactant mixture onto dolomite have been determined. The adsorbed amount of the Pluronics increases with increasing concentration and reaches plateau. An increase of adsorbed amounts of anionic surfactant onto the mineral surfaces (dolomite) has been observed at the presence of Pluronic copolymers. The adsorption effect of triblock copolymers has been investigated on the zeta potential of dolomite at the water suspension. The interaction of anionic surfactant with copolymers causes a decrease of zeta potential to small amount due to the deformation of double electrical layer. The adsorbed non-ionic Pluronic layer partially screens the surface charge of mineral particles, and thus, reduces the zeta potential. On the other hand, the adsorption of anionic surfactant and copolymer caused a decrease of negative value of zeta potential both investigated minerals. The stability of dolomite suspension depends on the both copolymer and sodium oleate concentrations.

Keywords: Pluronic, adsorption, synergism, zeta potential, dolomite, surfactant, sodium oleate. 


\section{INTRODUCTION}

The use of adsorbing copolymer and surfactant to modification of mineral surface and colloidal dispersion behavior represents an industrially significant problem. For instance, the pharmaceutical industry requires an adjustment of the drug surface to the human body environment. Thus, the use of amphiphilic macromolecules adsorbed onto the biodegradable materials is a new way of medicine delivery $[1,2]$.

Pluronics are triblock copolymers of polyethylene oxide (PEO) and polypropylene oxide (PPO). The adsorption of Pluronic macromolecules depends on the hydrophobicity of the sorbent surface. In the case of hydrophilic surface, two PEO blocks attach to the surface. On the other way, the adsorption onto the hydrophobic surface is realized by PPO block which anchors to the surface. The conformation of adsorbed Pluronic molecules onto different surfaces depended on the PPO/PEO ratio $[3,4]$. The adsorption behavior of triblock copolymers at the solidliquid interface is naturally richer than that of diblock copolymer. Pluronics can adsorb to the surfaces either in a pancake or brush-like configuration. Polymer brushes are usually made of uncharged polymers most often polyethylene oxide (PEO). The adsorption amount increases almost monotonically with the balk concentration of copolymer.

The molecular architecture of Plutonic determines specific applications. Pluronic have been applied in both drug and gene delivery systems [5, 6], as a biological protector of bacterial cell and protein adhesion [7, 8]. The application of Pluronics can increase the membrane hydrophilicity and fouling-resistance ability [9].

Polymer-surfactant interactions were subject to intensive theoretical and experimental investigations especially at both the solution-air and solid-solution interfaces [10-13]. Mixed adsorption of polymers and surfactants at solid/liquid interfaces has been studied much less. A majority of these investigations have been focused on the adsorption onto the hydrophobic surfaces. Relatively low quantities of papers were devoted to polymer-surfactant adsorption onto hydrophilic surfaces. It was shown, that the adsorption of Pluronic F108 onto silica was extremely sensitive on SDS concentration and ionic strength [14].

This paper involves a detailed study of the adsorption of Pluronic and ionic surfactant (sodium oleate) on the dolomite surface. Subsequently, the zeta potential and suspension stability have been analyzed. 


\section{MATERIALS AND METHODS}

\subsection{Materials}

\subsubsection{Minerals}

Natural dolomite is from old quarry Kletno (Lower Silesia, Poland). The dolomite is relatively pure $\left(98 \% \mathrm{MgCa}\left(\mathrm{CO}_{3}\right)\right)$. Mineral samples were first crushing in agate mortar and then fractionating on the sieves. The fine fraction of $-40 \mu \mathrm{m}$ was used for adsorption studies. The dolomite has density $2.77 \mathrm{~g} / \mathrm{cm}^{2}$ and the surface area was $1.92 \mathrm{~m}^{2} / \mathrm{g}$ for dolomite. The specific surface areas of mineral powder was determined by nitrogen dynamic flowing technique providing BET surface area using Micromeritics FlowSorb II 2300. The main particle size of mineral particles was $18.39 \mu \mathrm{m}$ for dolomite. It was measured by using Malvern Mastersizer 2000 equipment.

\subsubsection{Chemicals}

Amphiphilic block copolymers of poly(ethylene oxide)poly(propylene oxide)-poly(ethylene oxide) - Pluronics, with different molar mass and different contents of hydrophilic and hydrophobic segments were a gift from BASF Corporation. The necessary information about Pluronics PE 10500 and PE 6800 are presented in Table 1.

Table 1. Some information of Pluronics used in experiments.

\begin{tabular}{cccc}
\hline Pluronic & Structure & $\begin{array}{c}\text { Average } \\
\text { molecular } \\
\text { weight }\end{array}$ & $\begin{array}{c}\text { Molar mass } \\
\text { of PEO block }\end{array}$ \\
\hline PE 6800 & $\mathrm{EO}_{72} \mathrm{PO}_{28} \mathrm{EO}_{73}$ & 8000 & 1750 \\
$\mathrm{PE} 10500$ & $\mathrm{EO}_{37} \mathrm{PO}_{56} \mathrm{EO}_{37}$ & 6500 & 3250 \\
\hline
\end{tabular}

As an anionic sodium oleate was used. The reagent was purchased from Alfa Aesar GmbH \& Co and was used without other purification. Tannic acid, used to determination of the Pluronics concentration, was obtained from Fluka Chemical Company. The reagent was also used without of further purifications. 


\subsection{Methods}

\subsubsection{Adsorption tests}

Adsorption experiments were determined by surfactant and Pluronic depletion measurements at the room temperature $20 \pm 1{ }^{\circ} \mathrm{C}$. The equilibrium adsorbed amount of Pluronic or ionic surfactant reached within $16 \mathrm{~h}$.The one-step adsorption isotherms were determined by solution depletion method. $50 \mathrm{~cm}^{3}$ of solutions of known concentrations were poured inside glass tubes together with the adsorbent $(0.5 \mathrm{~g})$. The suspensions were shaken and after reaching the equilibrium the samples were centrifuged and the supernatants were analyzed. The concentration of Pluronics in the supernatants was measured according to tannic acid method described by Tsurumi et al. [15]. The complexation between tannic acid and PEO block of Pluronic gives turbidity. The turbidity was established by measuring the absorbance at $600 \mathrm{~nm}$. Helios UV-Vis Spectrophotometer (Thermo Electron Corporation) was used for these measurements. Equilibrium concentrations of sodium oleate was determined using an extraction method [16].

The procedure of surfactant/copolymer mixture adsorption was carry out in the following way. The surfactant solution was first added to the mineral suspension, after the equilibrium was obtained, the copolymer solution was added.

\subsubsection{Zeta potential measurements}

Zeta potential measurements were performed using the commercially available equipment ZetaSizer Nano ZS from Malveren. Dilute suspensions were prepared by mixing $0.05 \mathrm{~g}$ of mineral powder in $100 \mathrm{~cm}^{3} 1 \mathrm{mM} \mathrm{NaCl}$ solution. The suspensions were ultrasonicated for 5 minute before measurements. The measurements were carried out in the temperature range between $20-22^{\circ} \mathrm{C}$. The $\mathrm{pH}$ of suspension was natural (for dolomite $\mathrm{pH}$ 10.4-10.6). The ZetaSizer Nano apparatus calculates the zeta potential by determining elektrophoretic mobility. The zeta potential was calculated by applying the Henry equation. The function of $\mathrm{\kappa a}$ depends on the particle size and the reciprocal of double layer thickness. In our case ka was $>>1$.

\subsubsection{Stability measurements}

Turbiscan Lab Expert to study the sedimentation behavior of dolomite suspensions was used. $20 \mathrm{~cm}^{3}$ of dolomite suspension was ultrasonificated for $1 \mathrm{~min}$ and it was placed in a measuring chamber. Each 
dolomite sample was measured for $35 \mathrm{~min}$ and a single scan was collected every $1 \mathrm{~min}$. The transmission profiles of dolomite suspensions versus times were collected. The low value of transmission responds to high dolomite suspension stability.

\section{RESULTS AND DISCUSSION}

The properties of a binary mixture of nonionic surfactants in water at the water-air interface have been investigated [17]. The synergetic effect in the micelle formation for TX100 and TX165 mixture was discussed. The understanding of the adsorption role in practical application. Synergy in coadsorption of collectors is a promising direction in flotation research since achieving the alike surface property at a lower concentration of the reagents is possible.Tri-block copolymers of polyethylene oxide (PEO) and polypropylene oxide (PPO) known as Pluronic can adsorb to dolomite surface. The conformation of adsorbed Pluronic layer depends on the degree of hydrophobicity of the solid surface. The isotherms of Pluronics adsorption onto the hydrophilic surface of dolomite are presented in Fig. 1.

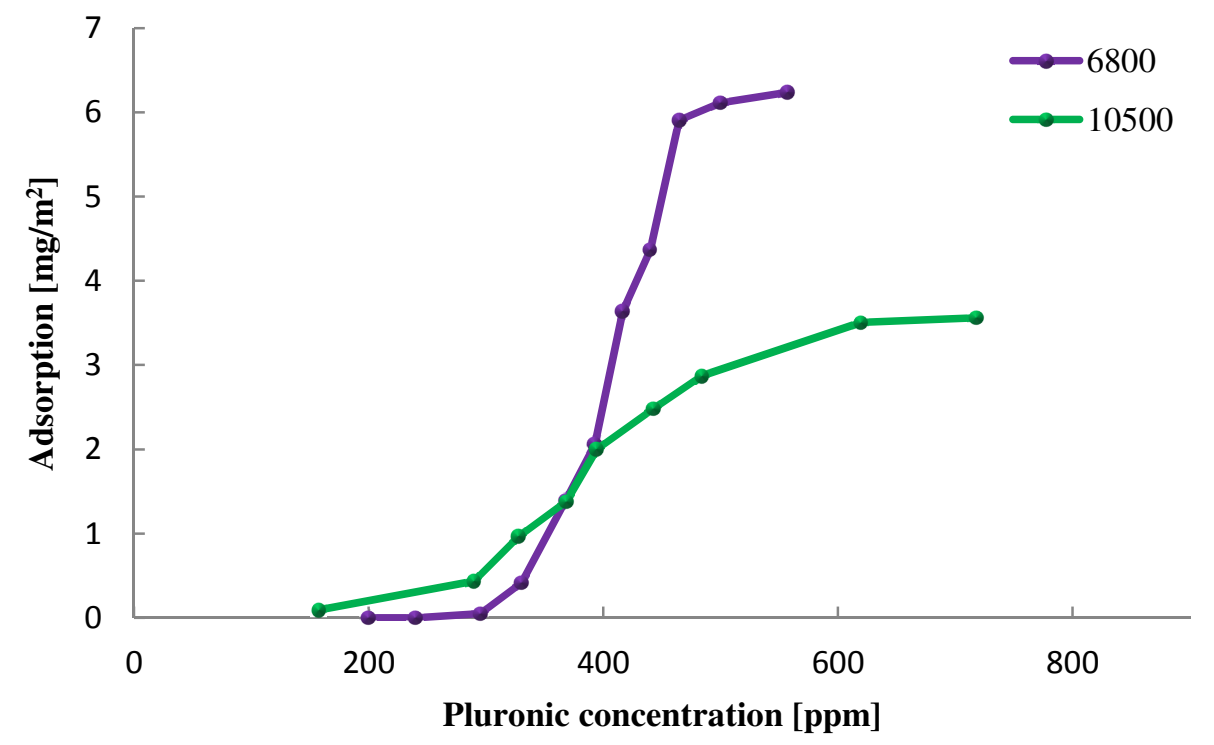

Fig.1. Adsorption of Pluronics on hydrophilic dolomite surface.

PEO groups were adsorbed preferentially on the hydrophilic surfaces. The obtained results confirmed this statement. The calculated 
surface concentrations of adsorbed copolymer molecules on the dolomite surface are presented in Table 2.

Table 2. Surface concentration of Pluronic onto mineral surface.

\begin{tabular}{cccc}
\hline Pluronic & Molecular weight & PEO/PPO ratio & $\begin{array}{c}\Gamma_{\text {dolomite }} \\
{\left[\mathrm{mg} / \mathrm{m}^{2}\right]}\end{array}$ \\
\hline 6800 & 8000 & 3.57 & 6.86 \\
10500 & 6500 & 1.0 & 3.18 \\
\hline
\end{tabular}

The results of adsorption of the mixture of Pluronic and anionic surfactant onto the and dolomite are presented in Fig. 2. The mixtures of surfactantpolymer most often perform better adsorption than individuals. When both components in the mixture adsorbed strongly on the solid, the mixture generally exhibits synergism in the study concentration region. As can see from Fig. 2 the synergistic interaction promotes the adsorption of the polymer (Pluronic 10500) in the mixed system.

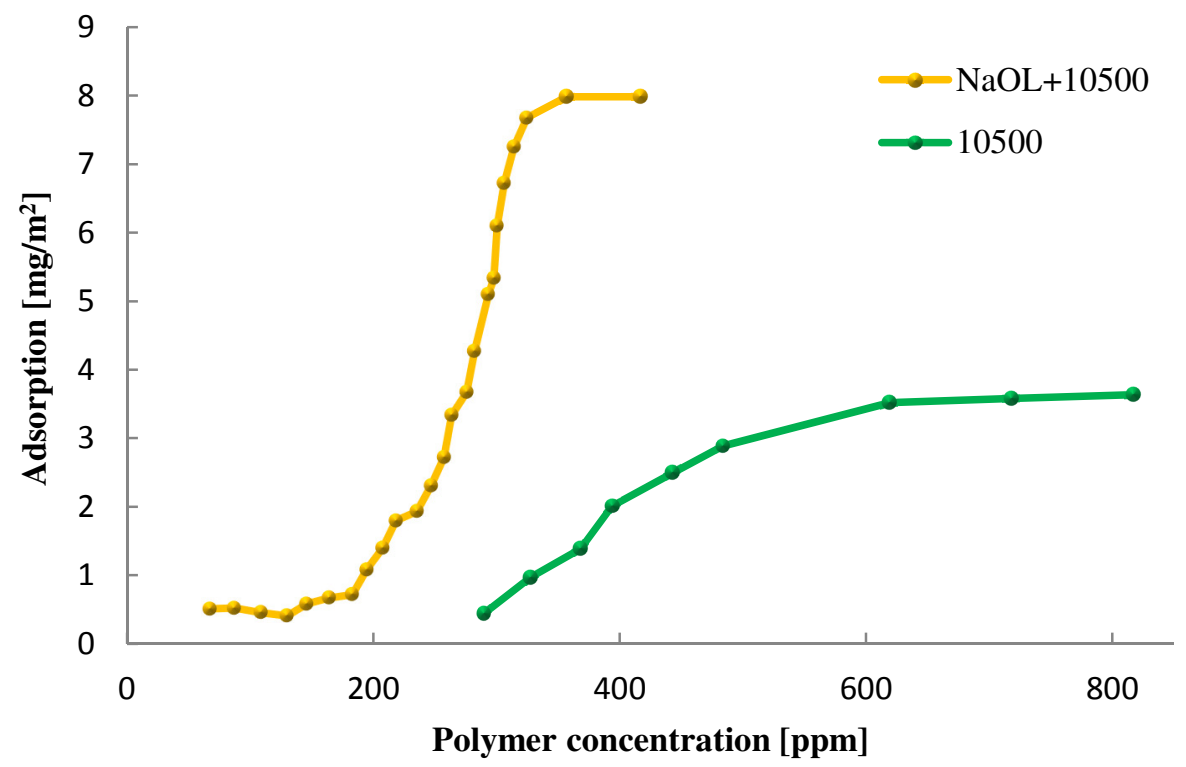

Fig. 2. Adsorption of Pluronic 10500 on the hydrophilic and hydrophobic dolomite surface.

The hydrophobic parts of copolymer molecules can anchored to hydrophobic part of anionic surfactant as it is schematically presented in 
Fig. 3. The adsorbed amount of Pluronic 10500 increases with increasing concentration and reaches plateau at $8.2 \mathrm{mg} / \mathrm{m}^{2}$ onto the hydrophobic surface and $3.7 \mathrm{mg} / \mathrm{m}^{2}$ onto the hydrophilic surface.

The surfactant molecules act as a bridge between the mineral surface and hydrophobic block of copolymer. This complex system was created on the schematic representation of PVD-SDBS complexes which was presented by Torn and coworkers [10]. When sodium oleate first interacts with the dolomite surface the mixed sodium oleate (SOL)/Pluronic complexes are formed in which the hydrophobic SOL moiety penetrates the PPO core of Pluronic (Fig. 3).

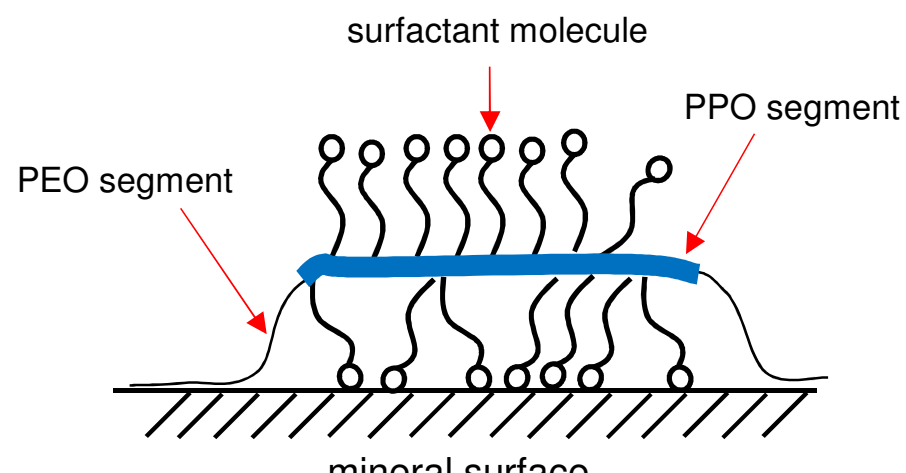

Fig. 3. Schematic diagram of Pluronic-surfactant system onto hydrophilic surface

The water suspension of dolomite particles showed $\mathrm{pH}$ equals 10.4. The isoelectric point of dolomite was at the vicinity this $\mathrm{pH}\left(\mathrm{pH}_{\text {iep }}\right.$ for dolomite is $\mathrm{pH}=10.2$ ). Upon adsorption of nonionic copolymers (Pluronic), the zeta potential of dolomite changed slightly (Fig. 4). It is certainly related to the $\mathrm{pH}$ condition. The natural $\mathrm{pH}$ of dolomite suspension is at the vicinity of the izoelectric point of dolomite.

Generally, slight changes in the zeta potential of dolomite in the presence of Pluronics (Fig. 4) are due to a shift in the place of shear plane. The screening effect of Pluronic molecules was supported by the other literature data [18] . 

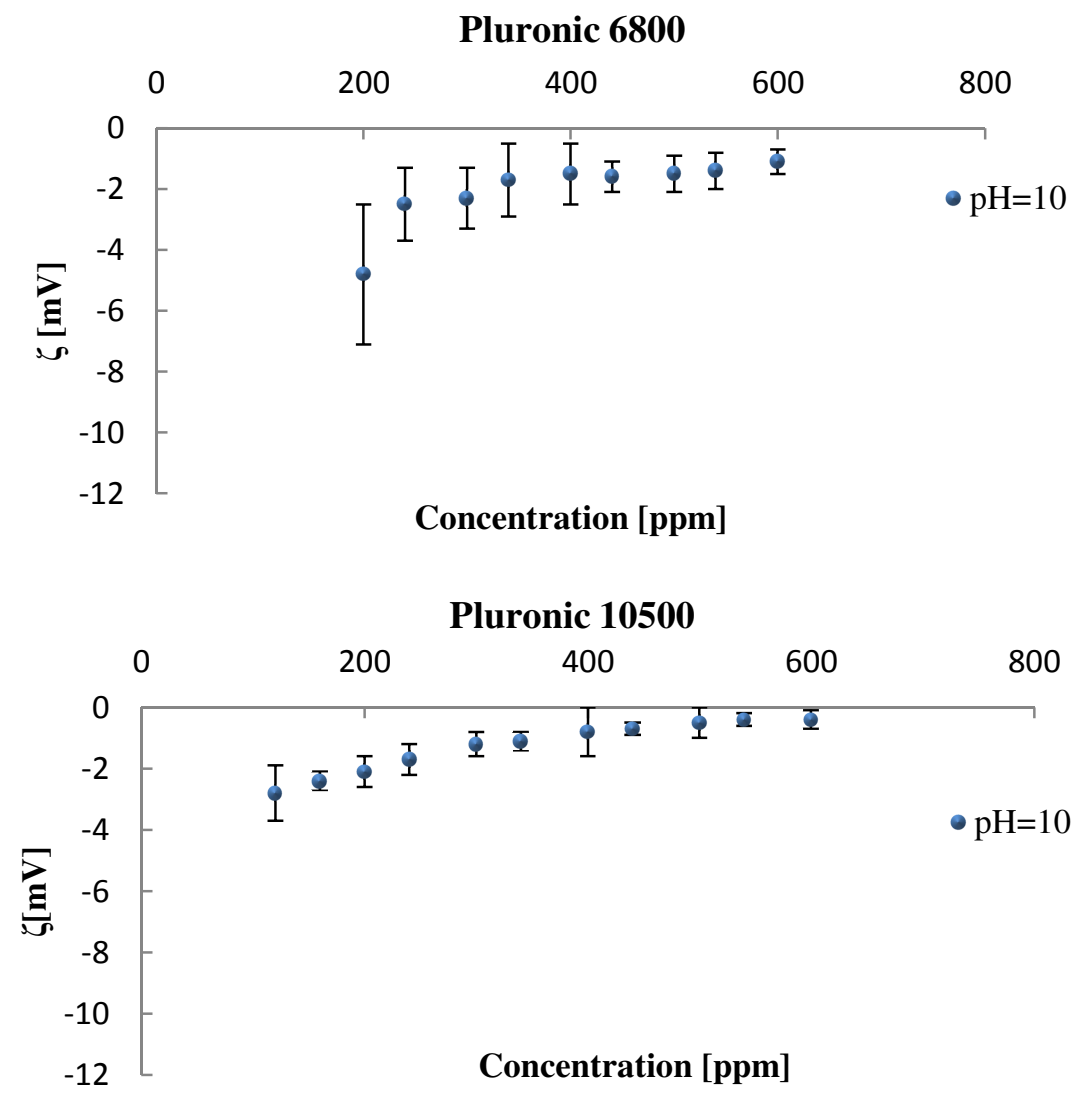

Fig. 4. The effect of copolymer concentration on zeta potential of dolomite.

Dolomite and sodium oleate

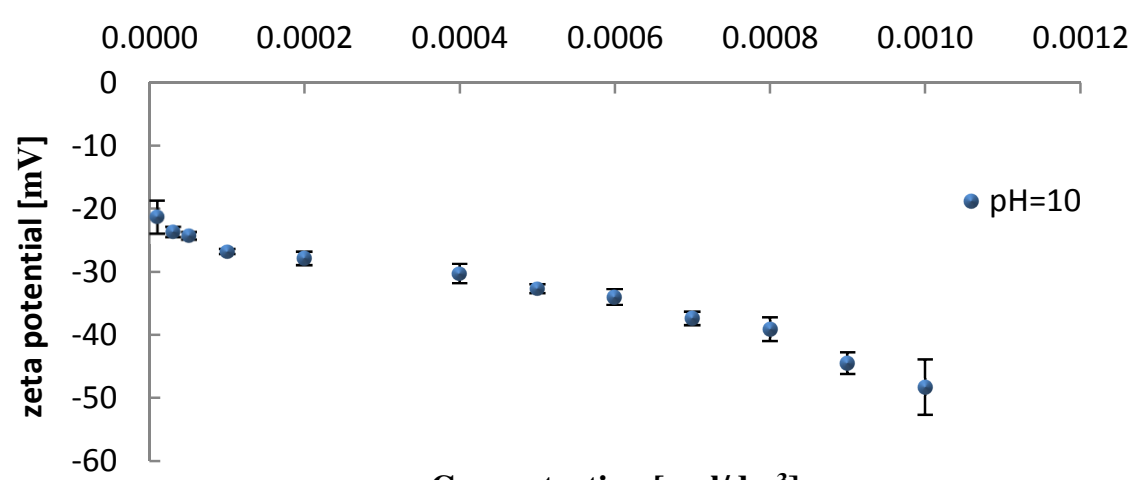

Concentration $\left[\mathrm{mol} / \mathrm{dm}^{3}\right]$

Fig. 5. The effect of sodium oleate concentration on the zeta potential of dolomite at $\mathrm{pH}=10$ 
The effect of Pluronic concentration on the zeta potential of Pluronicanionic surfactant complex at the constant concentration of sodium oleate $\left(7 \cdot 10^{-4} \mathrm{~mole} / \mathrm{dm}^{3}\right)$ is presented at Fig. 6.

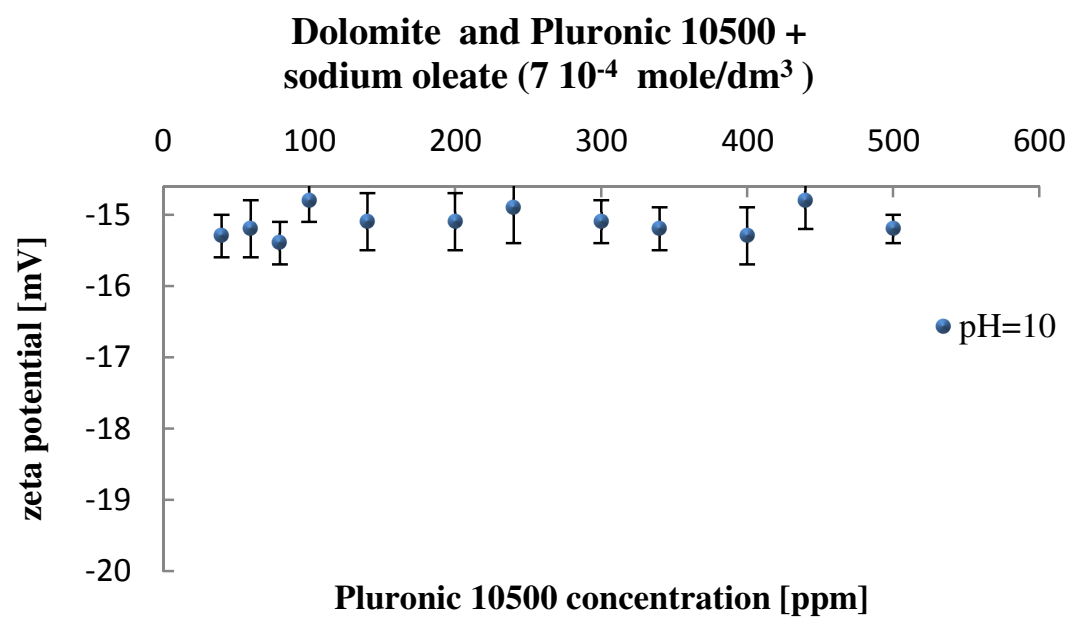

Fig. 6. The effect of Pluronic 10500 concentration on the zeta potential of dolomite.

Additional information on the behavior of the dolomite suspensions is the stability. The stability study of dolomite suspensions was carried by transmission profiles using Turbiscan MA2000. The effect of Pluronic concentration on the stability of dolomite suspensions was presented at Fig. 7.

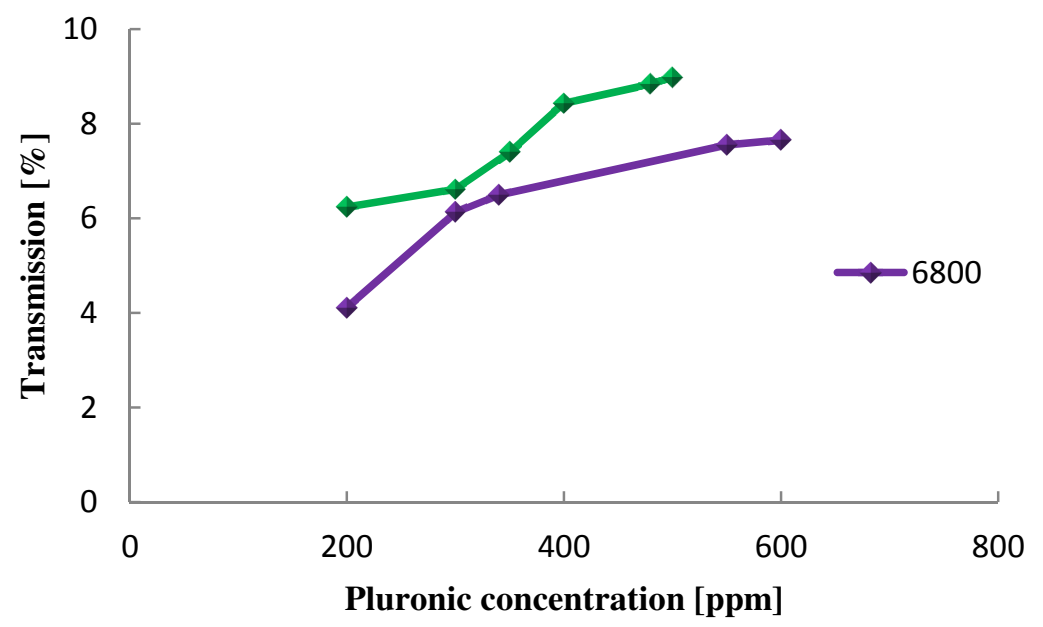

Fig. 7. Effect of Pluronic concentration on the stability of dolomite suspensions. 
As can be seen, the stability of dolomite suspension systematically decrease when the Pluronic concentration increase. It is evidenced by the high transmission. The addition of sodium oleate significantly deteriorates the stability of dolomite suspension (Fig. 8).

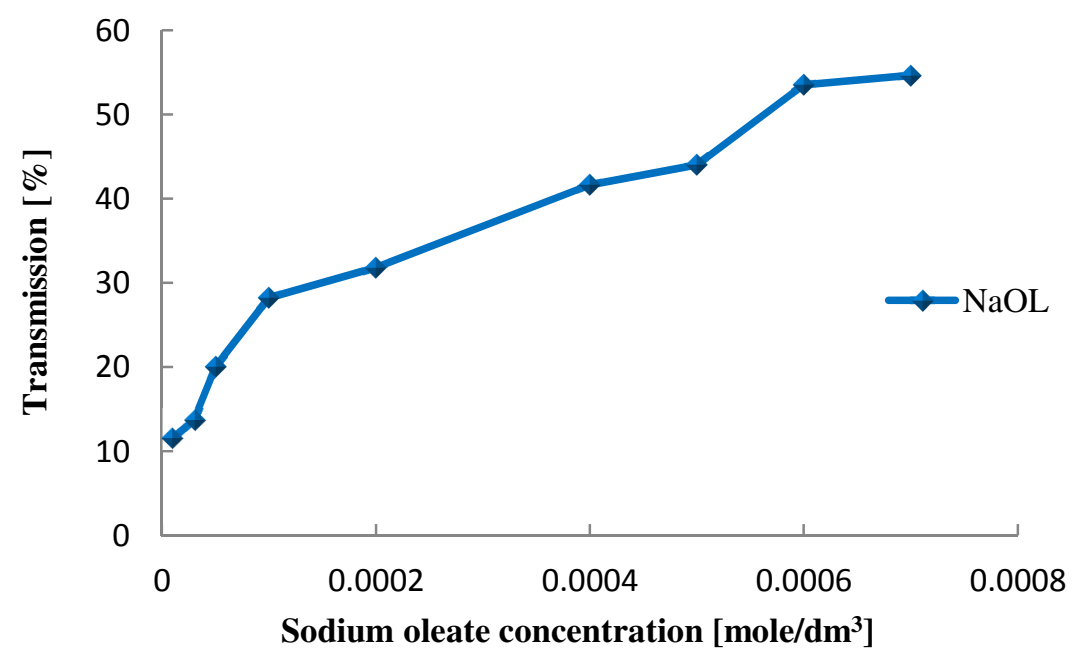

Fig. 8. Effect of sodium oleate concentration on the stability of dolomite suspension.

The behavior of dolomite suspension in the presence of sodium oleate and Pluronic 10500 is presented at Fig. 9. The addition of Pluronic to the hydrophobic suspension of dolomite (dolomite with sodium oleate) causes a dramatically increase of stability. The conformation of the adsorbed Pluronic 10500 macromolecules is more extended to the solution. The high stability of dolomite suspension occurs through steric stabilization. 


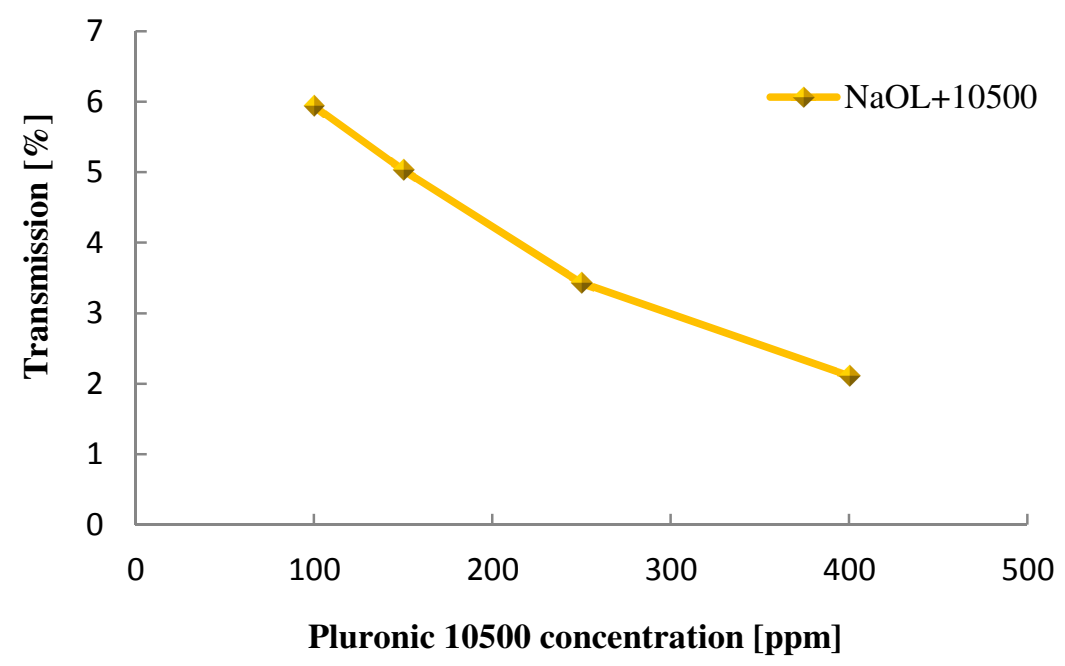

Fig. 9. Effect of Pluronic 10500 concentration on the stability dolomite suspension at the presence of sodium oleate

\section{CONCLUSIONS}

We have studied the adsorption behavior of triblock copolymers and anionic surfactants onto the solid-liquid interfaces. It is shown that the amount of Pluronic adsorbed on the dolomite surfaces dependents on the $\mathrm{PE} / \mathrm{PO}$ ratio. When the adsorption is realized together with surfactant an increase of Pluronic and surfactant adsorbed amounts was observed. It suggests that the synergistic effect is connected with the adsorption of Pluronic and surfactant on the mineral surface. The adsorption of Pluronic-anionic surfactant complex onto the mineral surface caused screening of negative values of zeta potential compare to adsorption of single surfactant. The stability results indicate that the Pluronic addition caused flocculation of dolomite suspensions. The stability of dolomite suspension in the presence of sodium oleate has low stability. The addition of Pluronic to dolomite suspension results in a drastic increase of its stability.

\section{ACKNOWLEDGMENTS}

This research was funded by the Faculty of Chemistry of Wroclaw University of Technology. 


\section{REFERENCES}

[1] N. Rapoport, Stabilization and activation of Pluronic micelles for tumor-targeted drug delivery, Colloids Surfaces B: Biointerfaces 16, 93-111, (1999).

[2] V.E., A. V. Kabanov, Pluronic block copolymers: Evolution of drug delivery concept from inert nanocarriers to biological response modifiers, J. Controlled Release, 130, 98-106, (2008).

[3] H. Terayama, K. Okumura, K. Sakai, K. Tprigoe, K. Esumi, Aqueous dispersion behavior particles by addition of surfactant and polymer, Colloids Surfaces B: Biointerface, 20, 73-77, (2001).

[4] A. Kapilashrami, M. Malmsten, K. Eskilsson, J-W. Benjamins, T. Nylander, Ellipsometric studies of nonionic block copolymers adsorbed at the solid/water and oil/water interfaces, Colloids Surfaces A. Physicochem. Eng. Aspects, 255, 181-192, (2003).

[5] A. J. Shar, T. M. Obey, T. Cosgrove, Adsorption studies of polyethers. Part II: adsorption onto hydrophilic surfaces, Colloids Surfaces A: Physicochem. Eng. Aspects, 150, 15-23, (1999).

[6] S. Govender, P. Swart, Surfactant formulations for multifunctional surface modification, Colloids Surfaces A: Physicochem. Eng. Aspects, 331, 97-102, (2008).

[7] V. A. Kabanov, E. V. Batrakova, V. Yu. Alakhov, Pluronic block copolymers as novel polymer therapeutics for drug and gene delivery, J. Controlled Release, 82, 189-212, (2002).

[8] E. K. Wesenberg-Ward, B. J. Tyler, J. T. Sears, Adhesion and biofilm formation of Candida albicans on native and Pluronictreated polystyrene, Biofilms, 2, 63-71, (2005).

[9] F. J. D. Taylor, R. K. Thomas, P. Penfold, Polymer/surfactant interactions at the air/water interface, Advance Colloid Inter. Sci. 132, 69-110, (2007).

[10] H. L. Torn, A. de Keizer, L. K. Koopal, J. Lykleme, Mechanism adsorption of poly(vinylpyrrolidne) and sodium dodecylbenzenesulfonate on kaolinite, J. Colloid Inter. Sci., 260, 1-8, (2003).

[11] R. Greenwood, P. F. Luckham, T. Gregory, The effect of particle size on the layer thickness of a stabilizing polymer adsorbed onto two different classes of polymer latex, as determined from rheological experiments, Colloids Surfaces A: Physicochem. Eng. Aspects, 98, 117-125, (1995). 
[12] O. Ortona, G. D’Errico, L. Paduano, V. Vitagliano, Interaction between cationic, anionic, and non-ionic surfactants with ABA block copolymer Pluronic PE6200 and BAB reverse block copolymer Pluronic 25R4, J. Colloid Inter. Sci., 301, 63-77, (2006).

[13] R. Zhang, C. Liu, P. Somasundaran, A model for the cooperative adsorption of surfactant mixtures on solid surfaces, J. Colloid Inter. Sci., 310, 377-384, (2007).

[14] D. A. Braem, D. C. Prieve, R. D. Tilton, Electrostatically tunable coadsorption of sodium dodecyl sulfate and poly(ethylene oxide)b-poly(propylene oxide)-b-poly(ethylene oxide) triblock copolymer to silica, Langmuir, 17, 883-890, (2001).

[15] D. Tsurumi, T. Yoshimura, K. Esumi, Adsolubilization of 2-naphtol into adsorbed layer of PEO-PPO-PEO triblock copolymers on hydrophilic silica, J. Colloid Inter.Sci., 297, 565-469, (2006).

[16] S. J. Zhang, S. Lee, J. W. Lee, Does SDS micellize under methane hydrate-forming conditions below the normal Krafft point, J. Colloid Inter. Sci., 315, 313-318, (2007).

[17] K. Szymczyk, B. Janczuk, The properties of a binary mixture of nonionic surfactants in water at the water/air interface, Langmuir, 23, 4972-4981, (2007).

[18] H. Liu, H Xiao, Adsorption of poly(ethylene oxide) with different molecular weights on the surface of silica nanopaticles and the suspension stability, Materials Letters, 62, 870-873, (2008). 